\title{
Approaching an outlook towards Human Aura-variation of Bio- Field having a dependence on person's karma/An exploration of scientific evidence of human aura
}

\author{
Avi Krishna Srivastava ${ }^{(1,2)}$ Shradha Singhvi $^{(1)}$ Virendra Singh $^{(1)}$ \\ ${ }^{1,2}$ Department of Sensors and Biomedical Engineering,Vellore Institute Of Technology, Vellore,632014,India
}

\begin{abstract}
Various life processes in human beings involve physiological and mental activity. Interestingly, electromagnetic field is associated with such activities[11]. Psychological perception of one's environment or a person's thought process induces characteristic electrical impulses in the brain. These signals travel throughout the body and emit out in the form of electromagnetic radiations which is termed as "Aura" or "Bio-Field Energy". The aura of a person is directly connected to the level of health of the person. Change in the Aura could be used to detect the person's health. Therefore, human health could be monitored by measuring the BioField Energy emitted from the body.

In this paper, a new hypothesis is introduced which tries to incorporate Human aura with science. We will discuss about the sixth sense, human's Karma and the level of energy.
\end{abstract}

Keywords; Aura, Bio-Field, electromagnetic radiations, sixth sense, human's karma.

\section{INTRODUCTION}

Paranormal by very etymology of term means beyond normal and thus has restricted understanding by normal human beings. Only the tiny drop of knowledge is known in the ocean. In the distant past, people admired things they could not explain and called them "miracles". In ancient days people were able to see Auras. Several paintings of people such as Buddha, Christ and their students were found with golden haloes around their heads, because some artists could able to see the actual Aura [12]. In Australia remote West Kimberleys one can find prehistoric cave paintings, many thousands of years old, depicting people with golden haloes.

Human body, from womb to tomb, continuously transmits signals within the body and around the body in its ecosystem through faint electric currents.

As electricity passes through a metal wire it causes an energy field or magnetic field.In a similar way when impulse passes through nerves it carries charge with it.As a result of this, it produces Bio-Field[13]. The produced magnetic field is very small in magnitude. Highly sensitive instruments are required to measure the magnitude of the magnetic field produced. Certain high level cameras have been developed which can detect the aura colors.[14]

The people's perception and thoughts, determine the outcome of the Bio-Field associated with them termed as Aura or Halo . For most common people the aura is so faint and weak that it is not visible by the naked eye. However for those who are evolved, spiritually and humanely haloes could be visible due to larger amount BioField accumulated inside and around them. Thus the golden aura around spiritual leaders like Budhdha, Mahavirji, idolized Hindu gods and goddesses, Christ etc.

\section{STRUCTURAL LEVEL OF AURA}

Aura is made of different colours.Each colour has its own significance and meaning. Some of the colors have been discussed below.

\begin{tabular}{|l|l|}
\hline \multicolumn{1}{|c|}{ COLOURS } & \multicolumn{1}{c|}{ MEANING } \\
\hline Black & Negativity \\
\hline Blue/ Blue-grey & Gives peace of mind/Fear of ideas \\
\hline Brick Red & Selfishness \\
\hline Bumt Orange & Opportunity/ helps in assimilation of new ideas \\
\hline Cream & Charming, acceptance \\
\hline Dark Brown & Unenlightened \\
\hline Dark Green & Jealousy \\
\hline Dark Grey & Problem intuition \\
\hline Dark Orange & Down to earth \\
\hline Dark Red & High energy/ a waming of danger \\
\hline Dark Yellow & Caution \\
\hline Deep Golden gold & Prosperity/spiritual love \\
\hline Off white & Peace of mind \\
\hline Pink & Unconditionallove, mother love \\
\hline Violet & Divine growth \\
\hline White & Hope, purity, sign of truth \\
\hline Aquamarine & Compassionate, sensitivity, parent \\
\hline
\end{tabular}


The structure of the AURA can be understood based upon the interpretation of each color in the various layers which together make-up the AURA. The human AURA very much depends upon and is a reflection of the human behavior and psychology and act as a connection between the mental and physical factors.[1]

According to presumption, it is this Aura which affects the society and brings changes in and around them. As it was found that several paintings of people such as Buddha, Christ and their students were found with different colored (mostly golden and white) haloes around their heads, and since all of them shared spirituality and peace of mind as common underscoring qualities, one can fairly associate the gold and white auras with these qualities

\section{BIO-FIELD}

Biofields are fields surrounding living biological objects [3]. It is linked with cellular activities and incudes the various healing process. They can have photonic, thermal, magnetic and electromagnetic components [4]. One possible influence of biofield phenomena is that they may act directly on molecular structures, changing the conformation of molecules in functionally significant ways[5]. Another influence is that they may transfer bioinformation carried by very small energy signals interacting directly with the energy fields of life, which is more recently known as the biofield [6]. Biofield is electromagnetic field existing very faintly around an organism. Comparing it with traditional fields, earlier it was believed it was just suggested as strong force as seen popularly among Hindus by 'Yogis' or 'saints' eventually this forces were researched and comprised of electric and magnetic fields and can be measured.

Several animals have the ability to perceive the Bio-field surrounding them. Animals have shown the ability to interact with the Earth's magnetic field eg.., Birds fly in a definite pattern. This pattern is formed when bird's magnetic fields interact and resonate with the other bird's magnetic field and with Earth's magnetic field. Similarly in Humans, if someone is looking from the back, the person could sense the feeling of being constantly observed, the reason could be that, the magnetic field of the person gets concentrated and interacts with the magnetic field of the other person. The magnetic field generated by the source basically disturbs the recipient's magnetic field as a result the person can anticipate someone's presence.

\section{Defining Energy}

Physics describes the word energy as the ability to do work and work is moving something against a force. There are lot of different kinds of energy in the world eg.., Kinetic Energy, Potential energy, Positive energy, Negative Energy, Neutral Energy etc.

Positive Energy- In terms of physics, anything which contains more number of protons compared to electrons are considered to have more positive charge and have positive energy. In terms of spiritual and religious level, if any person is joyful, enthusiastic and spreads happiness and gives positive vibes is considered to have a positive energy in him/her.

Negative Energy- In terms of physics, anything which contains more number of electrons compared to protons are considered to have more negative charge and negative energy. In terms of spiritual and religious level, if a person is wicked-minded and disseminate evil attitude giving negative vibes is considered to have a negative energy in him/her.

Neutral Energy- In terms of physics, anything which contains equal number of electrons and protons are considered to have equal charge and have neutral energy.

As stated by Moe "Everything is energy in the form of positive, negative and neutral.

The thoughts we think, the words we talk and the paths we walk effect everything that we do in life.

Therefore we must carefully watch our thoughts, words, visions, actions, people and our environments.

What we think, see, act and who we surround ourselves with, we will become one with this energy field."[7]

Defining "KARMA"

"KARMA" means that divine, omnipotent, omniscient Power which adjusts each effect to it's originating cause. It does this consciously, wisely and unerringly; therefore it is more than the mere operation of even an immutable law, if we regard this as acting mechanically or automatically, for Karma is the agent of Absolute Consciousness, and not one phenomenon occurs in all this manifested universe of which it does not take conscious note .[8]

\section{Hypothesis}

Considering all the theories and scientific facts, some important points can be laid. It is believed that when a person commits a sin or violates the other person, he or she have to experience the similar thing as a result of their deeds.

Law of Karma has a parallel in physics just as the energy gained by moving body is a function of the mass of the body and it's velocity, the Karma acquired by an individual is a function of the type of act and good will or bad will put by the ego in the act itself.[9] 
Correlating this with scientific approach, it can be presumed that if someone does harm to other person, a part of negative energy is transferred to other person.

The similar concept applies for positive energy as well. If a person does something good to someone, that means the person is giving his positive energy to that person. As law of conservation of energy states In a closed system, i.e., a system that isolated from its surroundings, the total energy of the system is conserved.[10]

Considering universe as a closed loop system and all the objects inside the system as an individual entity, the amount of energy in a person has to be maintained in equilibrium state. As a result the person receives in same amount of energy through external sources.

Eg if a individual has done something good and he has given away a part of his/her positive energy, therefore in order to maintain equilibrium, person will receive some positive energy, or in other words something good will happen to the person and vice versa with respect to negative energy.

\section{CONCLUSION}

Everything in this universe rush towards stability.

Creating an insight towards achieving an individual's stability, all the negative thoughts which are inside the human due to his/her karma could be neutralized by superimposing positive waves or energy from different human.

Observing all the facts of science and recalling the knowledge of energy, we would like to correlate person's karma with energy.

We can't say that the person will receive at that particular moment itself, but he/she will receive it. So when the person is doing bad to another person, this will give impact to his structure of aura. Person's Bio-Field will change accordingly.

\section{ACKNOWLEDGEMENTS}

Authors acknowledge the faculty Professor JOHN SUNDAR DAVID M - SSL and the team members VIT University, Vellore.

\section{REFERENCES}

[1]. Chhabra Gunjan (May- 2013) "Human Aura: A NEW VEDIC APPROACH IN IT” ISBN:978-93-82208-95-2

[2]. Sixth Sense:Science begins to Explain How we Sense Electric Fields Retrieved on 3/20/2017 from http://themindunleashed.com/2015/10/sixth-sense-science-begins-to-explain-how-we-sense-electric-fields.html

[3]. Rubik, B. (2002). The biofield hypothesis: Its biophysical basis and role in medicine. Journal of Alternative and Complementary Medicine, 8, 703-717.

[4]. Oschman, J. L. (2000). Energy Medicine: The Scientific Basis. Edinburgh: Churchill Livingstone

[5]. 'Measurement of human biofield and other energetic instruments' Retrieved on 20th march,2017 from http://www.rubysnake.com/science-reiki.html

[6]. Rubik B et al: Manual healing methods. Alternative medicine: expanding medical horizons, Washington, DC, 1994, US Government Printing Office, NIH Publication No. 94-066.

[7]. Everything is energy in the form of positive, negative and neutral Retrieved on Mar 12, 201 By Moehttp://gnosticwarrior.com/everything-is-energy-in-the-form.html

[8]. Karma: A Study of the Law of Cause and Effect, Jerome A. Anderson. Introduction

[9]. Bansi Pandit(2005) Explore Hinduism retrieved from https://books.google.co.in/books?id=PT5h4IjBMk0C $\& p g=P A 75 \& 1 p g=P A 75 \& \mathrm{dq}=$ law+of+conservation+of+energy+related+to+human+deeds\&source= bl\&ots=Pj7 18outfJ\&sig= AIzAeGOcDi1NzkdtR9r7PmcjTPU\&hl=en\&sa=X\&ved=0ahUKEwiVmbLas7XTAhUFM48KHT-3Da0Q6AEIOzAD\# $\mathrm{v}=$ onepage $\& \mathrm{q}=$ law $\% 20 \mathrm{of} \% 20 \mathrm{co}$ nservation $\% 20 \mathrm{of} \% 20$ energy $\% 20$ related $\% 20$ to $\% 20$ human $\% 20 \mathrm{deeds} \& \mathrm{f}=$ false

[10]. Law of conservation of energy, By Mark E. Tuckerman Retrieved on 04/21/2017 from http://www.nyu.edu/classes/tuckerman/adv.chem/lectures/lecture_2/node4.html

[11]. Monitoring the Human Health by Measuring the Biofield "Aura": An Overview by Shreya Prakash, Anindita Roy Chowdhury, Anshu Gupta on May 2015

[12]. How to see and READ the AURA: Part 1 retrieved on 03/25/2017 from http://www.thiaoouba.com/seeau.htm

[13]. Human Electric Energy retrieved on 03/25/2017 from http://www.spiritualgarden.net/info/human+electricity.html

[14]. What Color Is Your Aura? Maybe This Camera Can Tell You by Amy Hobbs retrieved on 03/25/2017 fromhttps://fstoppers.com/other/what-color-your-aura-maybe-camera-can-tell-you-5216 